\title{
ESCENARIOS DE FRAGILIDAD POLÍTICA, BALANCE POLÍTICO. GUATEMALA 2010-2011
}

\author{
Scenarios of political fragility, political balance. Guatemala \\ 2010-2011
}

\author{
RENZO LAUTARO ROSAL
}

Universidad Rafael Landívar

\section{RESUMEN}

En 2010 y 2011, la democracia guatemalteca experimentó procesos en que dificultaron la gobernabilidad. Ambos años representaron la segunda parte del gobierno presidido por el Ingeniero Álvaro Colom. La expectativa inicial del gobierno de supuesta orientación socialdemócrata pasó a rápido debilitamiento. Los programas sociales, inicialmente la punta de lanza de su gestión, dieron paso a su uso clientelar. El interés de la ex primera dama en participar en las elecciones de finales de 2011 y el posterior "divorcio presidencial" supuso un mayor grado de desgaste y pérdida de credibilidad del gobierno. El adelanto del proceso electoral, la debilidad del Tribunal Supremo Electoral TSE, la continuidad del frágil sistema de partidos políticos, el excesivo y opaco financiamiento privado electoral vinculado, en gran parte, al crimen organizado, generaron un proceso electoral paradigmático. Las opciones partidarias representaron un espectro reducido, conservador y dominado por opciones autoritarias. A nivel económico, a pesar de que el país no estuvo afectado por los efectos de la crisis económica mundial, el debilitamiento en el manejo de las finanzas públicas, el aumento de la deuda pública a niveles nunca antes conocidos y las consecuencias de la serie de desastres naturales ocurridos anualmente como consecuencia del cambio climático, generaron un escenario complejo con serias consecuencias para los siguientes gobiernos. Los niveles de criminalidad y violencia se mantuvieron altos, solo por debajo de Honduras y El Salvador. La presencia de las redes del crimen organizado y en particular del narcotráfico se generalizaron por todo el país. Las elecciones 2011 se desarrollaron en un clima de debilidad de la institucionalidad electoral, altos niveles de violencia electoral y una lucha entre carteles por el control territorial, destacando el avance de los Zetas.

Palabras clave: democracia, criminalidad, pobreza, estabilidad macroeconómica, partidos políticos, impunidad, narcos, corrupción, elecciones.

\footnotetext{
ABSTRACT

In 2010 and 2011, the Guatemalan democracy experienced processes which hampered governance. Both years accounted for the second part of the Government headed by the engineer Álvaro Colom. The initial expectation of alleged Government guidance became its rapid weakening. Social programs, the initial strategy of his management, led to a patronage. The interest of the presidents Colom ex wife in participating in elections in late 2011 and the subsequent "presidential divorce" meant a greater degree of wear and loss of credibility of the Government. The advancement of the electoral process, the weakness of the Supreme Electoral Court (Tribunal Supremo Electoral), the continuity of the fragile system, of political parties, excessive and opaque private campaign financing linked to organized crime, sparked a paradigmatic electoral process. Political Parties choices represented a reduced spectrum,
} 
conservative and dominated by authoritarian options. In a economic level, although the country was not affected by the effects of the global economic crisis, the weakening in the management of public finances, the increase in the public debt to levels never before known and the consequences of the series of natural disasters that occurred annually as a result of climate change, generated a complex scenario with serious consequences to the following Governments. Levels of crime and violence remained high in Guatemala, just below Honduras and El Salvador. The presence of organized crime and in particular drug trafficking networks was even throughout the country. The 2011 were held in a climate of weak electoral institutions, high levels of electoral violence and a struggle between cartels for territorial control, highlighting the advance of los Zeta organized crime group.

Key words: Democracy, crime, poverty, economic stability, political parties, impunity, narcos, corruption, elections.

\section{COYUNTURA ECONÓMICA}

En el período 2010-2011, la actividad económica mostró algunos signos de recuperación, después de los años 2008 y 2009, caracterizados por la desaceleración de la economía mundial que impactó medianamente en la economía nacional. Los flujos de exportaciones aumentaron en forma permanente. De US\$ 6,025.3 millones en 2006, a US\$ 8,466.2 millones en 2010. Esa cifra representó un aumento del 17,4\% respecto al 2009, donde se registraron ingresos por US $\$ 7,213$ millones. Para 2011, se proyectó un crecimiento total de las exportaciones entre $13,7 \%$ y $15,4 \%$.

Los fenómenos climáticos de 2010 generaron efectos adversos en rubros como camarón, pescado, langosta $(-25,6 \%)$, vegetales $(-13,75 \%)$ y frutas $(-1,6 \%)$, madera y manufacturas $(-11,6 \%)$. Hubo daños a la infraestructura productiva como consecuencia de la erupción del volcán de Pacaya, la tormenta Ágata, y el invierno irregular. La CEPAL calculó los daños en US \$1,553 millones, unos Q 12,424 millones.

Las importaciones 2010 alcanzaron los US\$13,836 millardos, comparado con los US\$11,500 millardos de 2009 (aumento del 20\%). El déficit comercial fue de US\$ 5,370 millardos (en 2009 fue US\$ 4,317.6 millardos). Para 2011 las importaciones aumentaron $14 \%$, ascendiendo a US $\$ 14,260$ millardos. ${ }^{1}$

La deuda pública aumentó en forma alarmante. En 2009 fue de Q. 26,209.9 millones, mientras en 2010 fue de Q. 36,769.2 millones. Entre 2010 y 2011 la deuda pública creció como consecuencia de la disminución de los ingresos del Estado, la no aprobación de la reforma fiscal y el incremento sostenido del gasto público. En 2010 el ritmo inflacionario fue de 5,39 (el más bajo desde el 2000, con excepción del 2009, que fue de -0,28).

El Producto Interno Bruto nacional (PIB) creció solamente $0,5 \%$ en 2009, a causa de los efectos de la crisis económica internacional. En 2010 el crecimiento fue de 2,6\%, ligeramente superior a la proyección de 2,4\%, del FMI. ${ }^{2}$

http://www.banguat.gob.gt/estaeco/boletin/

Banco de Guatemala. Informe de indicadores macroeconómicos 2010. Enero 2011. Guatemala. 
Cuadro 1: Algunos indicadores económicos

\begin{tabular}{lcc}
\hline \multicolumn{1}{c}{ Rubro } & 2010 & 2011 \\
\hline Ranking de competitividad (posición) & 78 & 84 \\
Índice Doing Business (posición / total países analizados) & $100 / 183$ & $101 / 183$ \\
Inversión extranjera directa (US\$ millones) & 805.8 & 686 \\
Ingreso de turistas (millones) & 1.9 & 1.8 \\
Ingreso de divisas por turismo (US\$ millones) & 985.6 & 937.2 \\
\hline
\end{tabular}

Fuente: elaboración propia con base en datos del Foro Económico de Competitividad 2010.

En 2010 el déficit fiscal creció respecto al 2009 (3,0), ascendiendo a 3,4\% del PIB. La carga tributaria en 2009 fue de 10,4\%, y en 2010 de 10,5\%. ${ }^{3}$ Esos porcentajes son inferiores al $13 \%$, considerado en los Acuerdos de Paz como el mínimo deseable.

Las finanzas públicas en 2010 estuvieron marcadas por: a) trabajar con un presupuesto público que se venía arrastrando de un año previo y que no obedecía a la realidad económica del momento; b) mayor endeudamiento; c) fenómenos naturales (tormenta Ágata, erupción del volcán de Pacaya y el copioso invierno) que presionaron al alza el gasto público; d) cambios de ministro responsable de la cartera, que afectó la percepción sobre manejo de la política fiscal de los agentes económicos.

En 2010 Guatemala mejoró su posición en el ranking de competitividad del Foro Económico Mundial donde, pese a encontrarse en una de las posiciones más bajas a nivel latinoamericano, ha tenido buen desempeño en los últimos años. Esa mejoría no fue sostenible, ya que en 2011 retornó a la posición de 2008, motivado por la inestabilidad del proceso electoral. En el índice Doing Business del Banco Mundial se ha tenido un desempeño positivo en forma constante, ${ }^{4}$ pasando de la posición 116 (2008) a la 101 en 2011.

La inversión extranjera mostró cierto retroceso. Las políticas de promoción de nuevas operaciones fueron desfavorecidas por la situación de inseguridad y los débiles incentivos para mejorar el clima de negocios. Disminuyó la inversión en 2011, afectada por el retiro de empresas de capital extranjero, especialmente del sector de la maquila de prendas de vestir.

En 2010 se experimentó una cifra histórica de turistas, alcanzando casi los dos millones de visitas. Para 2011, disminuyó en 10\%, por los hechos de violencia que afectaron a turistas y las advertencias de gobiernos, como Estados Unidos, que restringió los flujos

3 Banco de Guatemala. Informe de indicadores macroeconómicos 2010. Enero 2011. Guatemala.

4 Gobierno de la República (SEGEPLAN). Informe del Gobierno de Álvaro Colom, IV Informe del Presidente al Congreso de la República 2012. 
tradicionales y motivó el descenso del ingreso de divisas, de US\$1,321.7 millones en 2008 a US\$ 937.2 en $2011 .^{5}$

\section{COYUNTURA SOCIAL}

La coyuntura social fue dominada por dos problemas fundamentales: los persistentes niveles de pobreza e inequidad y los altos niveles de violencia y criminalidad.

\subsection{Pobreza y desigualdad que no ceden}

Aumentaron los programas y recursos públicos para la atención focalizada de las poblaciones en condiciones de pobreza y Pobreza extrema, pero está lejos que la estructura económica advierta cambios profundos, estables y reorientadores de la situación de exclusión en que están sumidas poblaciones, especialmente del área rural. El gobierno de Álvaro Colom implementó los programas de cohesión social. El programa "Transferencias Monetarias Condicionadas" fue el más importante, siendo ejecutado en 307 municipios. $^{6}$

La población entre 15 y 29 años de edad, uno de los segmentos más vulnerables a la pobreza, en especial de las comunidades rurales y lejanas a los centros urbanos, fue beneficiada por el avance de las capacidades educativas pero no en cuanto a posibilidades de empleo digno. La Encuesta Nacional de Juventud ENJU 2011 reveló que 7 de cada 10 jóvenes solo han concluido la educación básica ( 9 años de estudio). El $5,1 \%$ de los jóvenes tiene estudios universitarios, y solo el $0,1 \%$ cuenta con postgrado. ${ }^{7}$

Los avances de la gratuidad de los servicios públicos de salud influyeron en la disminución de los casos de mortalidad infantil y materna. A pesar de ello, fueron evidentes las insuficiencias en materia de infraestructura hospitalaria, de recursos humanos, equipos y medicinas.

En educación, la tasa neta de matriculación mostró cierto avance en 2010, comparado con el año previo. En 2011 hubo cierta disminución ocasionada por la inconsistencia del año escolar, las huelgas del sector magisterial y el proceso electoral.

Cuadro 2: Niveles de probeza en Guatemala

\begin{tabular}{ccc}
\hline Pobreza total & Pobreza & Pobreza extrema \\
\hline $51,01 \%$ & $35,80 \%$ & $15,21 /$ \\
\hline
\end{tabular}

Fuente: elaboración propia, con datos del Instituto Nacional de Estadística, INE.

5 Gobierno de la República (SEGEPLAN). Informe del Gobierno de Álvaro Colom, IV Informe del Presidente al Congreso de la República 2012.

6 Gobierno de la República (SEGEPLAN). Informe del Gobierno de Álvaro Colom, IV Informe del Presidente al Congreso de la República 2012.

$7 \quad$ Gobierno de la República. Encuesta Nacional de Juventud, octubre de 2011. 


\subsection{Inseguridad y violencia generalizadas}

En el período 2010 y 2011, Guatemala se ubicó como uno de los países latinoamericanos con mayor tasa de homicidios por cada cien mil habitantes. Después de Honduras y El Salvador que ocupan el primer y segundo lugar respectivamente, el país se ubica en el cuarto lugar en América Latina, solo superado por Venezuela ${ }^{8}$. En 2011 hubo cierta disminución, pero no la necesaria para dejar ese puesto.

Guatemala es el país de la región con mayores pérdidas económicas, como consecuencia de la violencia (cuadro 4).

La situación alarmante de la violencia fue resultado de la presencia y alta movilidad de las redes de criminalidad, especialmente del narcotráfico. Guatemala ha sido lugar clave para la logística y distribución de la droga, pero se han iniciado actividades de negociación y fabricación de drogas sintéticas. La cercanía geográfica del principal destino mundial de las drogas (EE.UU.), sumada a la debilidad y cooptación de las instituciones

Cuadro 3: Países latinoamericanos con tasas más elevadas de homicidios, 2010-2011 $(40 / 100.000)$

\begin{tabular}{lcc}
\hline País & Homicidios $/ 100.000$ hab. 2010 & Homicidios / 100.000 hab. 2011 \\
\hline Honduras & 82,1 & 86,0 \\
El Salvador & 66,0 & 66,0 \\
Venezuela & 48,0 & 48,0 \\
Guatemala & 41,4 & 38,6 \\
Colombia & 33,4 & 32 \\
\hline
\end{tabular}

Fuente: elaboración propia, con base en Crimen y Violencia en Centroamérica, un Desafío para el Desarrollo, BID, 2011.

Cuadro 4: Costos económicos de la violencia en Centroamérica, 2010

\begin{tabular}{lcc}
\hline País & Millones US\$ & $\%$ PIB \\
\hline Guatemala & 289 & $1,43 \%$ \\
El Salvador & 271 & $1,99 \%$ \\
Honduras & 61 & $1,31 \%$ \\
Nicaragua & 38 & $0,96 \%$ \\
Costa Rica & 96 & $0,58 \%$ \\
\hline
\end{tabular}

Fuente: elaboración propia, con base en Crimen y Violencia en Centroamérica, un Desafío para el Desarrollo, BID, 2011. 
gubernamentales, favoreció un entorno favorable al desplazamiento sin control de los grupos locales, aliados a los carteles mexicanos. La lucha por el control territorial, que se inició en las zonas fronterizas con México y Belice, se desplazó al interior del país y las fronteras con El Salvador y Honduras. La capacidad de desplazamiento, contracción y mutación de estas redes criminales en operaciones aparentemente legales superó las limitadas capacidades de las fuerzas de seguridad, civiles y militares. Se incrementó la actividad de los carteles mexicanos, producto de las acciones del gobierno mexicano y sus propias "necesidades" de expansión, aseguramiento de territorios y búsqueda de aliados en Centroamérica.

Las redes criminales crearon importantes alianzas con las pandillas juveniles o maras. Guatemala desplazó a El Salvador, siendo el segundo país en Centroamérica con mayor número de maras y el segundo en número de miembros, por detrás de Honduras (cuadro 5).

El 2010 concluyó como descenso en el número de muertes e incremento en la brutalidad y saña de los hechos de violencia. 2011 se caracterizó por mantener esa constante y el aumento de las extorsiones. ${ }^{9}$

La Comisión Internacional contra la Impunidad en Guatemala (CICIG) inició en 2007 y renovó a pedido del Estado de Guatemala una nueva ampliación para 2009-2011. En septiembre 2010, el presidente Colom solicitó una ampliación para el período 2011-2013. El actual Presidente, que tomó posesión en enero 2012, declaró su intención de solicitar a Naciones Unidos un nuevo período de dos años. La Comisión es un órgano independiente de apoyo al Ministerio Público, la Policía Nacional Civil y otras instituciones del Estado en la investigación de un número limitado de casos delicados y difíciles, con la intención de probar el funcionamiento de cuerpos ilegales de seguridad y aparatos clandestinos de seguridad y efectuar el desmantelamiento de estos grupos. ${ }^{10}$

Cuadro 5: Cálculo de afiliación a maras, por país (2011)

\begin{tabular}{lcc}
\hline \multicolumn{1}{c}{ País } & Miembros de mara & No. de maras \\
\hline Honduras & 36.000 & 112 \\
Guatemala & 14.000 & 434 \\
El Salvador & 10.500 & 4 \\
Nicaragua & 4.500 & 268 \\
Costa Rica & 2.660 & 6 \\
Panamá & 1.385 & 94 \\
\hline
\end{tabular}

Fuente: Comisión de Jefes de Policía de Centroamérica y el Caribe. Documento del Banco Mundial: Crimen y Violencia en Centroamérica, un Desafío para el Desarrollo, 2011.

9 Gobierno de la República (SEGEPLAN). Informe del Gobierno de Álvaro Colom, IV Informe del Presidente al Congreso de la República 2012.

10 Naciones Unidas. Acuerdo entre la Organización de las Naciones Unidas y el Gobierno de Guatemala relativo al establecimiento de una Comisión Internacional contra la Impunidad en Guatemala (CICIG), Nueva York, Estados Unidos, diciembre de 2006. 
Cuadro 6: Comparación de tasa de homicidios, 2000-11.

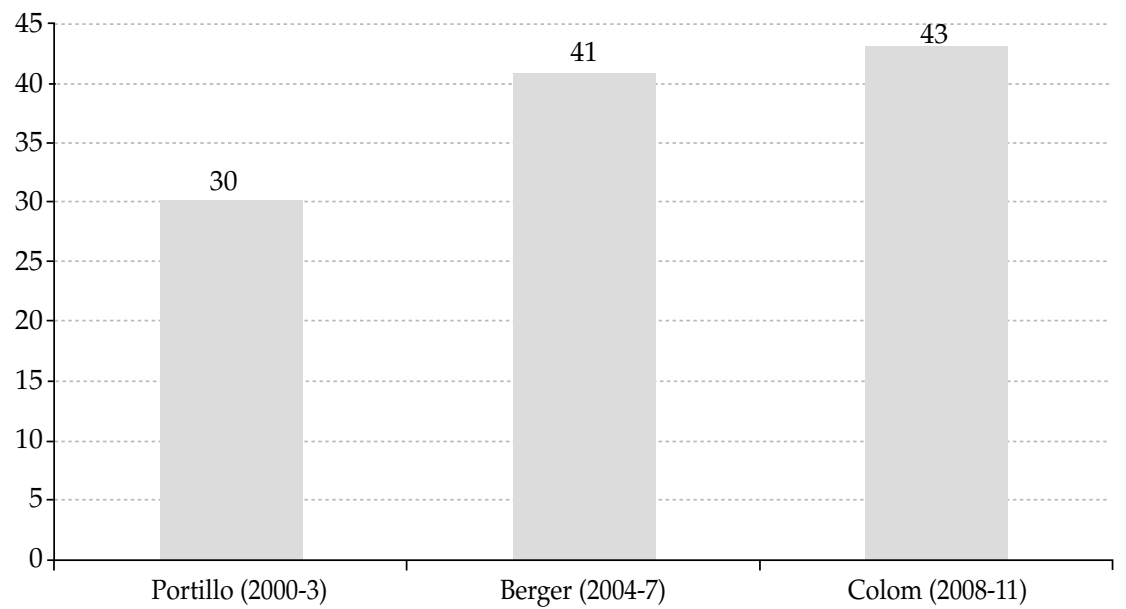

Fuente: Carlos Mendoza, CABI, 2012.

\section{LA MITAD DEL MANDATO, SE ACELERARON LOS ESCENARIOS DE FRAGILIDAD}

Los años 2010 y 2011 conformaron la segunda mitad del mandato de Álvaro Colom como Presidente de la República. Al deterioro tradicional que se ha observado en la segunda parte de todos los gobiernos de la era democrática (a partir de 1986), se agregaron factores especiales que aceleraron esa caída, como el llamado Caso Rosenberg.

\subsection{0, un año violento}

Enero inició con un incremento de la criminalidad, con el asesinato de pilotos y ayudantes de buses de rutas urbanas y extraurbanas. En 2009 fallecieron 120 pilotos. Las extorsiones se han generalizado, especialmente en las áreas urbanas, dando como resultado el abandono de colonias de la periferia citadina, cierre de negocios, asesinato de quienes se negaron o retrasaron los pagos a las bandas criminales, integradas por miembros de pandillas (maras), donde también estuvieron implicados propietarios de buses, choferes, ayudantes y criminales que operan desde las cárceles.

Se fortalecieron las acciones gubernamentales para encarcelar a cabecillas nacionales del narcotráfico. El incremento de las acciones de los Zetas procedentes de México, su objetivo de forzar a alianzas para ampliar su cobertura en Guatemala y países vecinos (El Salvador y Honduras), los enfrentamientos con narcos locales fueron algunas de las situaciones que incrementaron la persecución apoyada por el gobierno de Estados Unidos. De esa cuenta, en enero se anunció que uno de sus objetivos es la familia Lorenzana, lográndose la captura de dos de sus miembros a finales de 2011. 


\section{El caso Rosenberg y la CICIG ${ }^{11}$}

A inicios de ese año, la Comisión Internacional contra la Impunidad en Guatemala, CICIG, informó que el abogado planeó su propia muerte. Informó que los dos empresarios Valdés Paíz (primos del asesinado) pagaron a unos sicarios para que lo mataran, sin saber que se trataba de su familiar. Con esta información se exculpó al gobierno. La conclusión de la CICIG fue que Rosenberg planificó su inmolación, simulando que era contra un extorsionista que quería matarlo. "El que dio la instrucciones (de su asesinato) fue el mismo Rosenberg", enfatizó el jefe de la CICIG. Esa Comisión jugó un papel no solo de investigar y llegar a esas conclusiones, sino para contener el proceso de ingobernabilidad y sacar a flote la gestión del presidente Colom. En julio, los hermanos Valdés Paíz, supuestos autores del asesinato, se entregaron a la justicia.

\section{El caso Portillo}

Un hecho histórico fue la captura de ex presidente Alfonso Portillo, señalado de varios delitos ocurridos durante su mandato (1998-2002), en especial haber triangulado en su favor recursos públicos y donaciones provenientes de Taiwán. El caso no tiene precedente en la historia política de Guatemala, al ser el primer mandatario conducido a la justicia. El caso se ha retrasado por las acciones de sus defensores y la lentitud del sistema de justicia. En marzo se autorizó su extradición a Estados Unidos, aunque primero debe afrontar un proceso de peculado en Guatemala.

Un paso positivo de la administración del presidente Colom fue el inicio de la reforma policial. Se nombró a la activista de derechos humanos Helen Mack como responsable del proceso.

\section{Enmendar un craso error}

El Congreso de la República convocó a la elección del Fiscal General, proceso que se convertiría en una elección compleja, donde intervinieron sectores sociales para promover la repetición de la elección, a partir de los graves señalamientos contra quien fue inicialmente electo. Nuevamente el Ejecutivo fue sometido a desgaste y la CICIG contribuyó a la estabilización de la situación. En mayo, la comisión de postulación establecida por ley ratificó la nómina de candidatos a Fiscal General. El presidente Colom juramentó a Conrado Arnulfo Reyes Sagastume como Fiscal General y Jefe del Ministerio Público. En plena crisis, renunció Carlos Castresana, Comisionado de la CICIG, quien denunció una campaña de desprestigio en su contra y exigió la destitución del recién nombrado Fiscal General, argumentando su vinculación con el crimen organizado ${ }^{12}$. La Corte de Constitucionalidad ordenó repetir la elección. El nuevo proceso dio como

11 El abogado Rodrigo Rosenberg fue asesinado el 10 de mayo de 2009 en la zona 14 de la ciudad capital, mientras paseaba en bicicleta. Para consumar el hecho, pidió ayuda a sus primos y empresarios de apellidos Valdés Paíz. En una grabación hecha pública al día siguiente, el abogado Rosenberg señaló como responsable de su muerte al presidente Colom, lo cual ocasionó una situación de extrema inestabilidad que puso en riesgo la continuidad de su mandato.

12 Guatemala Visible, monitoreo de medios, 2010. 
resultado la elección de Claudia Paz (diciembre 2010), con lo que finalizó la crisis. En julio la ONU nombró al ex Fiscal General de Costa Rica, Francisco Dall’Anesse Ruiz, nuevo comisionado de la CICIG.

\section{Evidencias de la cooptación institucional}

Como muestra de la cooptación de las instituciones públicas por parte de las redes criminales, especialmente del narcotráfico, se hizo pública la sustracción de armas y municiones de bodegas del ejército, que estarían en poder de los Zetas. Esa institución negó los señalamientos, pero las evidencias fueron concluyentes.

Los organismos Ejecutivo y Legislativo, como parte de la estrategia para oxigenar y recobrar la credibilidad a partir de los últimos sucesos, establecieron un proceso de diálogo nacional para impulsar proyectos de leyes, entre los que se encuentran el de empresas privadas de seguridad, extinción de dominio, alianzas público-privadas y desarrollo rural. Con excepción del último, las leyes fueron aprobadas en 2011.

Desde 2009 sectores de la sociedad civil y partidos políticos mostraron dudas sobre el manejo político y financiero de los programas de cohesión social. Una de las consecuencias de esos señalamientos fue la resolución de la Corte de Constitucionalidad, que ordenó la destitución del ministro de Educación por no entregar los datos del Programa Mi Familia Progresa, pese a una orden judicial que le obligaba. A lo largo del mandado del presidente Colom otros ministros fueron destituidos por señalamientos de corrupción. La alta rotación en el Gabinete fue uno de los signos que contribuyeron al deterioro de la administración pública.

\section{Llamados de atención}

El apoyo del gobierno de Estados Unidos se ha focalizado en varios frentes, siendo uno de ellos la lucha contra el narcotráfico. En marzo seww recibió la visita de la Secretaria de Estado, Hillary Clinton, a quien los Presidentes de Centroamérica solicitaron mayor apoyo para combatir el narcotráfico y la inseguridad. En septiembre se conoció un informe del Instituto de Estudios Estratégicos del Pentágono de Estados Unidos, donde advierte que Guatemala podría convertirse en un narco-Estado debido a la actividad de narcotraficantes mexicanos que han traspasado las fronteras. En contraste, la institucionalidad responsable de esos frentes (Ministerio de Gobernación) continuó enfrentando serios problemas, especialmente por la vinculación de oficiales y agentes con redes criminales, actos de corrupción y acciones de limpieza social.

\section{Ambiente preelectoral hostil}

La violencia preelectoral fue un signo distintivo del proceso que culminó con las elecciones generales realizadas en septiembre y noviembre de 2011. Se agregó el proceso de desgaste mutuo entre el partido oficial, Unidad Nacional de la Esperanza UNE y los partidos de oposición, liderados por el Partido Patriota PP, con el objetivo de sacar de la jugada a la precandidata oficial, Sandra Torres. Esa tendencia se incrementó en 
el segundo semestre de 2010 y en los meses previos a las elecciones. Los programas sociales coordinados por esa figura representaron el objetivo político. En contraposición, el gobierno puso en marcha una estrategia para desacreditar a antiguos miembros del ejército por su vinculación con violaciones a los derechos humanos ocurridas durante el conflicto armado interno.

La debilidad del Tribunal Supremo Electoral fue la principal característica del período pre y electoral. Fue evidente el desgaste institucional provocado por la politización del tribunal, la centralización y dificultades para tomar decisiones ${ }^{13}$. La anticipación de la campaña fue consecuencia de ese deterioro institucional. Todos los partidos desoyeron los llamados de tribunal, sociedad civil y medios de comunicación y con más de un año adelantaron sus campañas electorales. Las acciones del TSE por impedir esa anticipación fueron infructuosas. Ese proceso tuvo otro ingrediente especial: se llevó a cabo con dos documentos de identidad (cédula de vecindad y documento personal de identificación DPI), lo que complicó la operatividad.

El deterioro de las finanzas públicas se agravó. La emisión de bonos fue una de las estrategias del gobierno central para financiar el gasto público, en particular para hacer frente a las demandas crecientes de los programas sociales, utilizados como herramienta básica electoral. En mayo se aprobó la emisión de bonos del Tesoro por casi US\$ 600 millones, aunque los funcionarios aseguraban que esos recursos eran insuficientes. La aprobación de una reforma tributaria se hizo necesaria, la cual se concretó en enero de 2012 aunque no en la dimensión y con los alcances necesarios para sacar a flote las malogradas finanzas públicas.

Las alianzas electorales comenzaron a concretarse desde mayo, en especial en apoyo a la candidatura de la candidata oficialista. De esa cuenta, la UNE, la Gran Alianza Nacional (GANA) y el Frente Republicano Guatemalteco (FRG) oficializaron su alianza, siendo la primera ocasión en la historia donde partidos que han obtenido la Presidencia de la República en forma sucesiva y que fueron rivales políticos, se unen tras un único objetivo. ${ }^{14}$

\section{Cambio climático y nuevos escenarios de conflictividad}

Los efectos del cambio climático acecharon al país. A finales de 2011, en la Cumbre Mundial del Cambio Climático, Guatemala fue declarada como el segundo país en el mundo con mayor propensión a esos efectos. ${ }^{15}$ El período de invierno (mayo a octubre) ocasionó desastres naturales de gran magnitud. En 2010, el Congreso de la República decretó Estado de Calamidad Pública tras la erupción del volcán de Pacaya y la tormenta Ágata, que ocasionó la muerte de 172 personas. De acuerdo con el presidente Colom, el costo de la reconstrucción superó los US\$120 millones.

13 Universidad Rafael Landívar. Programa de Opinión Pública POP. Informes de la misión de observación electoral 2011.

$14 \quad$ FRG gobernó entre 1998 y 2002, la GANA entre 2003 y 2007 y la UNE de 2007 a 2011, llevando a la Presidencia a Alfonso Portillo, Óscar Berger y Álvaro Colom, respectivamente.

15 Naciones Unidas, Informe de la Décimo séptima conferencia de las Naciones Unidas sobre cambio climático (CP 17), Durban, Sudáfrica, 2011. 
La explotación de los recursos naturales (extractivas y proyectos hidroeléctricos) promovida en los dos últimos gobiernos fue sujeta a amplio debate. Desde 2005 se han realizado consultas comunitarias, cuyos resultados, aunque no son vinculantes, indican que las comunidades están en contra de esas actividades. En junio, el gobierno anunció que cumplirá con las medidas cautelares recomendadas por la Comisión Interamericana de Derechos Humanos (CIDH), que suspendieron los trabajos de la mina Marlín, para proteger las comunidades de los municipios de Sipacapa y San Miguel Ixtahuacán, Departamento de San Marcos, donde opera la mina. ${ }^{16}$ En 2011, en el marco de una negociación cuestionada, las partes negociaron el cierre de ese caso, por lo que la empresa implicada continuó sus operaciones. En julio, el Presidente de la República prorrogó por 15 años el contrato con la empresa Perenco, para extracción de petróleo, a pesar de la oposición de grupos ambientalistas.

\section{Pérdida de credibilidad}

Los medios de comunicación aumentaron sus críticas a la gestión del presidente Colom, quien denunció que ello era parte de un plan para desestabilizar su gobierno. Según mediciones de popularidad, su gobierno contaba con la aprobación de 46,2\% de los guatemaltecos, mientras el 53\% calificó negativamente su desempeño. El 46,1\% consideró que el principal problema del país es la delincuencia. El gobierno denunció la existencia de un supuesto plan de desestabilización, que buscaría dar un "golpe de mercado" para desplazar a las autoridades gubernamentales. En julio, el G4, integrado por la Procuraduría de los Derechos Humanos, las iglesias católica y evangélica y la Universidad San Carlos de Guatemala, criticó la falta de cumplimiento del Acuerdo Nacional para el Avance en Seguridad y Justicia, mientras la violencia recrudecía. La Convocatoria Ciudadana, que agrupó a más de 50 organizaciones sociales, hizo un llamado para que los tres organismos del Estado emprendieran combate frontal a la inseguridad, impunidad y desigualdad. La Oficina del Alto Comisionado de las Naciones Unidas demandó acciones firmes para detener la inseguridad, como parte de una política integral de Estado. Según cifras del Instituto Nacional de Ciencias Forenses, durante el primer semestre del 2010 murieron de forma violenta 3.235 personas, mientras el ministro de Gobernación aseguró que no contaba con recursos para hacer frente a la delincuencia y la criminalidad. En noviembre, el presidente Colom vetó el Decreto 37-2010, Ley del Indulto presidencial, que permitía la aplicación de la pena de muerte y restituye el recurso de gracia para los condenados.

Como una nueva acción para ganar credibilidad y detener el desgaste, en agosto fueron enviados a prisión ex funcionarios del gobierno presidido por Óscar Berger acusados por supuesta participación en ejecuciones extrajudiciales, narcotráfico, lavado de dinero, secuestros y extorsiones, entre otros delitos cometidos entre 2005 y 2007. ${ }^{17}$

16 Comisión Interamericana de Derechos Humanos. Informe de medidas cautelares. Mayo de 2010.

17 Se detuvo al ex director del Sistema Penitenciario, Alejandro Giammattei, y al ex jefe del Servicio de Investigación Criminal, Víctor Soto, y se ordenó la captura del ex ministro de Gobernación Carlos Vielmann y del ex director de la PNC, Edwin Sperisen. 
El Congreso de la República mostró pocos avances en la agenda legislativa. Las acciones de las bancadas de oposición (especialmente del Partido Patriota) obstaculizan el avance. El transfuguismo y las prácticas clientelares estuvieron a la orden del día.

En octubre se condenó a 40 años de prisión a dos ex integrantes de la Policía Nacional por la desaparición y muerte del líder estudiantil y sindical Fernando García (esposo de la actual diputada Nineth Montenegro). El gobierno insistió en la persecución de quienes estuvieron implicados en la violación de los derechos humanos durante el conflicto (ex militares), lo cual reabrió un amplio debate ya que otros sectores sindicaron a ex miembros de la guerrilla.

El Índice de Percepción de Corrupción (IPC) 2010, elaborado por Transparencia Internacional, señaló que Guatemala pasó de una calificación regular (3.4 puntos obtenidos en el 2009) a una mala (3.2 puntos), situándose en la posición 91 de los 178 países evaluados. ${ }^{18}$ En el Índice de Desarrollo Humano 2010, Guatemala ocupó el puesto 116 entre las 169 naciones evaluadas, con un IDH de 0,56; solo por delante de Haití en América. ${ }^{19}$

En el marco del proceso preelectoral, se abre un nuevo debate sobre la posibilidad que ex mandatarios participen como candidatos a la Presidencia. El alcalde de la ciudad capital y ex presidente Álvaro Arzú anuncia su intención de participar. Meses después la Corte de Constitucionalidad, en el marco de la prohibición constitucional, pone fin a esa posibilidad.

\section{LA COYUNTURA POLÍTICA EN 2011, ENTRE ELECCIONES Y ACUMULACIÓN DE CARENCIAS}

\subsection{Pacto no escrito para precipitar la campaña}

El año se caracterizó por el proceso electoral al centro de la agenda, el aumento de las acciones en favor y en contra de la candidatura de Sandra Torres, el aumento de las actividades criminales, el deterioro de la institucionalidad electoral, la desatención a lo establecido en la Ley Electoral y de Partidos Políticos y la designación de los nuevos magistrados de la Corte de Constitucionalidad.

La primera encuesta de intención electoral del año colocó al precandidato Pérez Molina (Partido Patriota PP) al frente con $42 \%$, seguido por Sandra Torres (Unidad Nacional de la Esperanza UNE) con $11 \%$ y Álvaro Arzú (Partido Unionista PU) con 6,7\% ${ }^{20}$ El Programa Mi Familia Progresa (MIFAPRO) fue bien evaluado, con 68\% de aceptación. A iniciativa del Tribunal Supremo Electoral, los partidos políticos suscribieron el Pacto Ético Político de cara al proceso electoral, documento ampliamente violentado por todas las organizaciones en los siguientes meses. Ese mismo tribunal reformó el reglamento de la Ley Electoral y de Partidos Políticos para aclarar la diferencia entre propaganda y

18 Transparencia Internacional. Índice de Percepción de Corrupción (IPC) 2010.

19 Programas de las Naciones Unidas para el Desarrollo. Informe de Desarrollo Humano, Guatemala, 2011.

20 El Periódico. Encuesta de intención de voto presidencial. Febrero, 2011. 
proselitismo. Las elecciones generales de final de año fueron las más alteradas en cuanto a adelanto, montos y fuentes del financiamiento privado (el techo del financiamiento privado fue situado en US\$ 5 millones, pero en la práctica esa cantidad fue sobrepasada por casi todos los partidos).

Entre enero y febrero se anunciaron las primeras candidaturas a la Presidencia y Vicepresidencia. El Partido Patriota anunció a Otto Pérez Molina y Roxana Baldetti, ambos provenientes fundadores del partido. La Unión del Cambio Nacionalista (UCN) proclamó las candidaturas de Mario Estrada y Mauricio Urruela; el primero, secretario general del partido, amigo cercano y funcionario durante el gobierno de Alfonso Portillo (sindicado de actos de corrupción cuando desempeñó el cargo de Secretario de Desarrollo Social), señalado también de vínculos con redes criminales.

\section{La candidatura en entredicho}

Un hecho sobresaliente fue el anuncio de Sandra Torres como precandidata del partido oficial UNE y su divorcio del presidente Álvaro Colom, lo cual motivó profundas críticas de diversos sectores de la vida nacional, incluyendo colectivos de sociedad civil, partidos, empresarios, ex constitucionalistas, gremios de profesionales, medios de comunicación, entre otros. La utilización de la figura del divorcio para destrabar una prohibición constitucional y posibilitar la participación electoral fue una artimaña que afectó la credibilidad del gobierno, fortaleció a la oposición liderada por el Partido Patriota y desencadenó críticas de la cooperación internacional. La posibilidad electoral de la UNE se centró en la base de apoyo lograda con los programas sociales, los recursos públicos utilizados y la correlación de fuerzas que se preveía lograr en la elección de los Magistrados de la Corte de Constitucionalidad, institución que en última instancia tendría la decisión que facilitaría o impediría esa participación. Los resultados de esa elección no fueron los esperados por la UNE, pero a ello se sumó que cada magistrado decidió por su cuenta y no respondió a los intereses del partido elector. El TSE sancionó a la UNE por la proclamación de Sandra Torres, actuación que no pasó de lo formal. Su hermana, Gloria Torres, renunció de la UNE y criticó al liderazgo del partido. En junio, el Registro de Ciudadanos rechazó la inscripción de la candidatura de Sandra Torres, por incurrir en Fraude de Ley. ${ }^{21}$

Una nueva alianza se consumó. Los partidos VIVA y Encuentro por Guatemala EG anunciaron su participación conjunta. El primero intentó participar en las elecciones 2007, pero su inscripción fue tardía y por ello negada. Encuentro por Guatemala es liderado por Nineth Montenegro, antigua activista de Derechos Humanos, diputada desde hace tres legislaturas y comprometida con la causa de la transparencia.

21 Fraude de ley: La Ley del Organismo Judicial, en el segundo párrafo del artículo 4 define al fraude de ley como: "Los actos realizados al amparo del texto de una norma que persigan un resultado prohibido por el ordenamiento jurídico, o contrario a él, se considerarán ejecutados en fraude de ley y no impedirán la debida aplicación de la norma que se hubiere tratado de eludir". 


\section{El rol de las instituciones académicas}

En abril las Universidades San Carlos de Guatemala, Rafael Landívar y la Asociación de Investigación y Estudios Sociales ASIES presentaron al Congreso de la República una propuesta para reformar la Constitución de la República en los artículos relacionados con seguridad y justicia. ${ }^{22}$ La propuesta fue debatida en el seno del organismo legislativo, en espacios académicos y de la cooperación internacional. En 2012 se resolverá la viabilidad de la iniciativa.

Como un intento tardío del Congreso de la República, presentó a la Corte de Constitucionalidad una consulta para reformar la Ley Electoral. Desde 2008 se han presentado 17 iniciativas de reformas a ese marco legal. El proceso electoral impidió que la discusión continúe, relevando las posibilidades para la siguiente legislatura.

En abril se presentó una nueva encuesta de intención electoral. Otto Pérez Molina (Partido Patriota PP) encabezó con 42\%, Sandra Torres (Unidad Nacional de la Esperanza UNE) con 21\% y Manuel Baldizón (Partido Líder) se ubicó tercero, con 3\%. ${ }^{23}$

\section{Convocatoria formal rebasada por los hechos}

La convocatoria a elecciones generales fue realizada por el Tribunal Supremo Electoral el 2 de mayo. La primera vuelta se llevó a cabo el 11 de septiembre y la segunda (en caso de ser necesaria) fue programada para el 6 de noviembre. De esa forma se abrió formalmente el proceso electoral aunque en la práctica todos los partidos llevaban más de un año de actividades. La UNE proclamó su binomio integrado por Sandra Torres y Roberto Díaz-Durán. El Partido Unionista oficializó la candidatura de Patricia de Arzú (esposa del alcalde capitalino y ex presidente Álvaro Arzú) y de Álvaro Rodas. El Partido VIVA anunció a Harold Caballeros (pastor de una iglesia neopentecostal y fundador de la Universidad San Pablo) y Efraín Medina (antiguo Rector de la Universidad estatal San Carlos). El partido CREO proclamó su binomio integrado por Eduardo Súger, rector de la Universidad Galileo, y Laura Reyes (profesional indígena) y el Frente Amplio a Rigoberta Menchú (Premio Nobel de la Paz) y Aníbal García. En ninguna elección previa se había dado tanta participación de personas procedentes del sector académico.

\section{Avance del crimen organizado}

En mayo ocurrió una matanza de campesinos en el Departamento de Petén (el más grande y alejado de la capital, con una extensa frontera con Belice y México) donde fueron asesinados 27 jornaleros. El hecho fue atribuido a los Zetas; el presidente Colom decretó Estado de Sitio en ese departamento. A pesar de los operativos, los responsables no fueron capturados. Los cuestionamientos sobre la efectividad del Estado de Sitio no se hicieron esperar. 
El primer foro electoral abordó los planes de seguridad de los principales candidatos. Ese tema fue ampliamente abordado en el proceso, y convertido en la principal bandera de las ofertas electorales.

En junio venció el plazo para empadronarse (tener derecho a votar). Se logró un aumento significativo de los ciudadanos aptos para votar (más de siete millones); por primera ocasión las mujeres son más en el padrón electoral. ${ }^{24}$

Las amenazas y hechos de violencia fueron una constante a lo largo del proceso electoral. En marzo la magistrada presidenta del TSE anunció amenazas de muerte. En junio asesinaron a dos candidatos a la alcaldía de San José Pinula, municipio del Departamento de Guatemala. Por esos hechos es capturado y juzgado otro candidato a esa alcaldía. Candidatos a concejos municipales, coordinadores de campañas locales y activistas fueron las principales víctimas de la violencia electoral. Al mes de julio, no menos de 30 candidatos y familiares habían sido asesinados. ${ }^{25}$

Las candidaturas cuestionadas de Sandra Torres y Harold Caballeros comenzaron a ser negadas por las instancias legales. El Registro de Ciudadanos rechazó ambas candidaturas. Los expedientes fueron trasladados al Tribunal Supremo Electoral y posteriormente a la Corte Suprema de Justicia, donde se ratificó la denegatoria. En agosto, la Corte de Constitucionalidad denegó en definitiva la inscripción de Sandra Torres, lo que despejó el proceso electoral a un mes de la primera vuelta. Ese mes, la Corte Suprema de Justicia autorizó la inscripción de Harold Caballeros. ${ }^{26}$

En julio ocurrió el asesinato del reconocido músico Facundo Cabral, hecho que consternó en el ámbito nacional e internacional. Después de las primeras investigaciones, se concluyó que quien conducía al cantautor hacia el aeropuerto La Aurora es un empresario con negocios de drogas y prostitución en países de Centroamérica. Era hacia él que se dirigía el ataque ordenado por otro empresario de origen costarricense.

La presencia de la CICIG fue un tema de amplio debate. Desde los sectores conservadores que debatieron la violación de soberanía, pasando por quienes defienden y forman parte de las redes criminales, hasta los que cuestionan sus limitados resultados. Durante 2011 se sumaron a las críticas el gremio de abogados y la Asociación de Jueces, este último molesta por el llamado a investigar a los jueces cuyas resoluciones han sido cuestionadas por su parcialidad en favor de grupos criminales.

\section{Por encima de las instituciones}

A mediados de 2011, el TSE arreció las denuncias en contra de los partidos que no informan sobre sus gastos de campaña, la superación del techo previsto, la debilidad de los controles de los partidos por registrar el origen de sus recursos y sus constantes

24 ASIES. Monografía: los Partidos Políticos Guatemaltecos en el proceso electoral. Julio, 2011.

25 Universidad Rafael Landívar. Programa de Opinión Pública POP. Informes de la misión de observación electoral 2011.

26 Universidad Rafael Landívar. Programa de Opinión Pública POP. Informes de la misión de observación electoral 2011. 
negativas a transparentar lo relativo a sus financiamientos. En septiembre, el Tribunal sancionó al Partido Patriota por sobrepasar el techo de campaña.

En julio, la Comisionada Presidencial de la Reforma Policial, Helen Mack, señaló al ministro de Gobernación, Carlos Menocal, por obstruir ese proceso de reforma, generando señalamientos mutuos que afectaron la continuidad de la iniciativa.

Otro acontecimiento que ensombreció fue la desaparición de Cristina Siekavizza y sus dos pequeños hijos en un condominio de la periferia capitalina. El caso de violencia intrafamiliar y secuestro sigue sin resolverse. El esposo (Roberto Barreda), principal sospechoso de los hechos, no ha sido capturado. La madre de éste (Beatriz de León), ex magistrada y ex presidenta de la Corte Suprema de Justicia, fue señalada por tráfico de influencias y encubrimiento de su hijo.

En otro hecho relacionado con el conflicto armado interno se condenó a militares que participaron en la masacre de Las Dos Erres, lo cual dio como resultado reacciones de sectores pro militares quienes iniciaron procesos de enjuiciamiento contra ex militantes de la guerrilla por acciones similares.

Sectores sociales expresaron su preocupación por la judicialización de la política y expresaron su interés en promover reformas electorales profundas. Las elecciones dejaron ver las debilidades del sistema de partidos y del TSE.

Los femicidios se incrementaron. En septiembre, la Procuraduría de los Derechos Humanos informó que Izabal, Guatemala, Escuintla y Quetzaltenango fueron los departamentos con más hechos. ${ }^{27}$ En ese mismo mes, domingo 11, se llevó a cabo la primera vuelta electoral. Otto Pérez Molina y Manuel Baldizón disputarían la segunda vuelta electoral. El primero no alcanzó el 40\% de los votos que proyectaba y generó una expectativa de triunfalismo. El Partido Patriota (PP) logró la mayoría de diputaciones. El partido oficial UNE en coalición con GANA obtuvo el segundo lugar en el número de diputaciones alcanzadas, resultado que no se esperaba. El partido VIVA informó que apoyaría al PP en segunda vuelta, pero su aliado en primera vuelta, Encuentro por Guatemala, no compartió esa decisión. El partido Líder oficializó una alianza de apoyo, integrada por: UNE, GANA, PAN, FRG, UCN, la candidata vicepresidencial de CREO y WINAQ.

Participaron 19 de los 28 partidos políticos inscritos legalmente. De ellos, seis no presentaron candidatos para binomio presidencial. Tres de los partidos tienen una antigüedad mayor a diez años, nueve tienen entre 3 y 9 años de creación y seis tienen dos años o menos. Estos datos constatan la alta fragmentación y volatilidad del sistema de partidos políticos, caracterizado por su multipartidismo extremo. Participaron diez binomios presidenciales (ocho en forma independiente y dos por coaliciones). Cuatro de los partidos participantes ejercieron el gobierno central: PAN, FRG, GANA y UNE. 28 
Cuadro 7: Cargos obtenidos para el Congreso de la República

\begin{tabular}{lcc}
\hline \multicolumn{1}{c}{ Partido } & $\begin{array}{c}\text { No. de diputados } \\
(14 \text { enero 2012) }\end{array}$ & $\begin{array}{c}\text { No. de diputados } \\
\text { (6 marzo 2012) }\end{array}$ \\
\hline Patriota & 57 & 62 \\
UNE & 40 & 12 \\
UCN & 14 & 16 \\
LIDER & 14 & 23 \\
CREO & 12 & 11 \\
GANA & 8 & 8 \\
VIVA-EG & 6 & 6 \\
Frente Amplio (Winaq-URNG-ANN) & 2 & 2 \\
PAN & 2 & 2 \\
Unionista & 1 & 1 \\
FRG & 1 & 1 \\
VICTORIA & 1 & 13 \\
Bloque independiente bajo liderazgo Roberto Alejos & 0 & 158 \\
\hline Total & 158 & \\
\hline
\end{tabular}

Fuente: elaboración propia, con base en datos del Tribunal Supremo Electoral.

- 138 diputados hombres y 20 mujeres (13\% del total).

- 80 diputados son nuevos (51\%) y 78 reelectos $(49 \%)$.

\section{Elecciones paradigmáticas}

Durante las elecciones se generaron más de 70 disturbios en elecciones municipales. Esos hechos se dieron en municipios donde los alcaldes buscaban la reelección. Ello motivó la repetición de elecciones en cuatro municipios y en uno más (Tectitán), por empate en el primer lugar. Álvaro Arzú es reelecto alcalde de la Ciudad de Guatemala. ${ }^{29}$

A pesar de las campañas y procesos de formación, las mujeres indígenas perdieron espacios en puestos de elección. El TSE fue criticado por la lentitud en la transmisión de los resultados, dificultades en la mecánica del voto, debilidad en la capacitación de las juntas receptoras de votos y problemas en la compatibilidad del padrón electoral. Las misiones de Observación Electoral informaron sobre problemas en los comicios: acarreo, problemas en realizar la observación, amenazas a observadores, problemas de documentación, inexperiencia de las juntas receptoras. Se criticó a las encuestadoras por fallar en sus estudios de intención. Juntas Electorales Municipales renunciaron por amenazas. Se generaron tensiones entre los magistrados del TSE, creando un ambiente

29 Universidad Rafael Landívar. Programa de Opinión Pública POP. Informes de la misión de observación electoral 2011. 
complicado para la segunda vuelta. La primera encuesta presentó a Pérez Molina en ventaja sobre Baldizón. Los dos candidatos finalistas participaron en un debate televisado, caracterizado por los señalamientos fuertes y la falta de contenido en sus propuestas. Trece integrantes del Comité Ejecutivo Nacional de la UNE renunciaron. El Auditor del TSE solicitó la suspensión del Partido Patriota por rebasar los gastos de campaña.

Días previos a la segunda vuelta electoral se informó que más de 10 alcaldes fueron electos pese a tener juicios por cuentas pendientes. El general Otto Pérez Molina fue electo con el 53\% de los votos válidos. Roxana Baldetti es electa la primera Vicepresidenta de Guatemala en su historia. Poco tiempo después se inició el proceso de transición bajo la coordinación de Eduardo Stein, ex Vicepresidente de la República. Como un hecho positivo, el Presidente electo anunció con prontitud los nombres de su gabinete. Se ratificó a la Fiscal General ante rumores de su destitución. Ante la pérdida de espacio y credibilidad del presidente Colom, el Presidente electo asumió protagonismo, generando acercamientos con diversos sectores e impulsando la transición.

Un hecho significativo fue la elección de Guatemala, con el voto de 191 representantes, como miembro No Permanente del Consejo de Seguridad de las Naciones Unidas.

El resquebrajamiento de la UNE se aceleró. Diputados reelectos renunciaron al partido, creando un grupo bajo el liderazgo de Roberto Alejos, quien presidió el Congreso de la República durante los tres años anteriores.

El año cerró con otro escándalo. Cristha Torres, sobrina de Sandra Torres, fue capturada por acusaciones de lavado de dinero y estafa.

En los últimos días de diciembre, veteranos del ejército y viudas de militares presentaron denuncias contra ex miembros de la guerrilla, por muertes de sus familiares, secuestros y asesinatos de embajadores en la época del conflicto armado.

Cuadro 8: Resultados elección presidencial (primera vuelta)

\begin{tabular}{lcc}
\hline Candidato y partido & No. de votos & Porcentaje \\
\hline Otto Pérez Molina, Patriota* & $1.597,937$ & $36,10 \%$ \\
Manuel Baldizón, Líder* & $1.004,215$ & $22,70 \%$ \\
Eduardo Suger, CREO & 735,728 & $16,6 \%$ \\
Mario Estrada, UCN & 385,932 & $8,7 \%$ \\
Harold Caballeros, VIVA-EG & 276,192 & $6,2 \%$ \\
Rigoberta Menchú, WINAQ-URNG-ANN & 142,599 & $3,2 \%$ \\
Juan Gutiérrez, PAN & 121,964 & $2,8 \%$ \\
Patricia de Arzú, Unionista & 96,870 & $2,2 \%$ \\
Alejandro Giammatei, CASA & 46,655 & $1,1 \%$ \\
Adela de Torrebiarte, ADN & 18,779 & $0,4 \%$ \\
\hline
\end{tabular}

Fuente: elaboración propia, con base en datos del Tribunal Supremo Electoral. 
Cuadro 9: Resultados elección presidencial (segunda vuelta)

\begin{tabular}{lcc}
\hline Candidato y partido & No. de votos & Porcentaje \\
\hline Otto Pérez Molina, Patriota & 2.300 .979 & $53,74 \%$ \\
Manuel Baldizón, Líder & 1.981 .003 & $46,26 \%$ \\
\hline
\end{tabular}

Fuente: elaboración propia, con base en datos del Tribunal Supremo Electoral.

\section{SÍNTESIS. UNA DEMOCRACIA CON FUNCIONALIDAD ARTIFICIAL}

La realidad observada en relación al comportamiento de la democracia durante 2010 y 2011 evidenció una situación crítica en términos de gobernabilidad, debilitamiento del ejercicio de ciudadanía y fragilidad de la institucionalidad. Una discusión planteada con fuerza fue si Guatemala se concibe como Estado fallido, narco-Estado, o Estado con serios problemas de gobernabilidad.

Guatemala no es un narco-Estado, aunque ha estado cerca de serlo. El país está sometido a amenazas crecientes, pero aún no se cruza la frontera en la medida que es un territorio bajo asedio, en disputa entre carteles locales asociados con carteles mexicanos. Hay problemas de corrupción y cuestionamientos de la institucionalidad, pero aún no hay cooptación total. Se implementaron, parcialmente, políticas de combate a las redes criminales con algunos resultados (captura de importantes líderes de grupos locales, lugartenientes y operadores de campo).

La principal amenaza al Estado democrático radica en que el objetivo constante de narcos y otras redes criminales (traficantes de armas, de mujeres, de niños; contrabandistas, robavehículos, defraudadores del fisco, entre otras) consiste en hacer fracasar sus funciones fundamentales (seguridad, sistema de justicia, institucionalidad, desarrollo económico, control de los partidos políticos, afectación de los servicios, pérdida de confianza ciudadana, debilitamiento de la imagen internacional). Buscar la inviabilidad, el estancamiento de iniciativas, la desesperación, la pérdida de esperanza son objetivos de esos grupos, cuya percepción se ve favorecida en la medida que los niveles de criminalidad se agravan, sumado a la falta de políticas para la generación de ingresos.

Son preocupantes los niveles de cooptación de las instituciones públicas. A todo nivel, desde las altas esferas de los poderes del Estado, pasando por los concejos municipales e instituciones autónomas y descentralizadas. En las pasadas elecciones se percibieron los niveles de infiltración. Se movilizaron más de US\$ 80 millones, monto que no tiene explicación solo con los capitales nacionales y legales. Campañas de candidatos a alcaldes y diputados fueron financiadas por capitales provenientes de actores ilegales.

También preocupan los avances para legitimar la presencia y actuación de las redes criminales. Esa estrategia crece en la medida que la presencia del Estado en los territorios no solo es escasa, sino gradualmente en abandono. En las zonas donde la precariedad 
es común, los narcos y sus redes han sabido moverse con total libertad; además, y en especial, en el caso de los narcos locales, provienen y han vivido siempre en esas localidades estableciendo lazos de relacionamiento cercanos y de dependencia mutua (las comunidades los necesitan para seguridad, generadores de empleo y otorgamiento constante de ayudas, y los narcos para control territorial, seguridad personal, mano de obra, servicios de inteligencia local, etc.). La pobreza ha sido el principal motivo de esas relaciones "perversas".

\section{REFERENCIAS}

Asociación de Investigación y Estudios Sociales ASIES. Iniciativa Think Tank. Monografía: los Partidos Políticos Guatemaltecos en el proceso electoral. Julio, 2011. Guatemala.

Asociación de Investigación y Estudios Sociales ASIES. Proceso electoral 2011, información y datos básicos. Septiembre 2011. Guatemala.

Banco de Guatemala. Informe de indicadores macroeconómicos 2010. Enero 2011. Guatemala.

Banco de Guatemala. Informe de indicadores macroeconómicos 2011. Enero 2011. Guatemala.

Banco Interamericano de Desarrollo. Crimen y Violencia en Centroamérica, un Desafío para el Desarrollo, 2011. Estados Unidos.

Banco Mundial. Perfil de datos Guatemala (en lìnea) www.bancomundial.org

Comisión de Jefes de Policía de Centroamérica y el Caribe. Informe sobre el Estado de la Seguridad Ciudadana en la región. 2011.

Central American Business Intelligence. Análisis de criminalidad. Publicado en Plaza Pública. 2011. Guatemala.

Comisión Interamericana de Derechos Humanos. Informe de medidas cautelares. Mayo 2010. Costa Rica.

El Periódico. Encuesta de intención de voto presidencial, febrero, 2011. Guatemala.

El Periódico. Encuesta de intención de voto presidencial, abril 2011. Guatemala.

Gobierno de la República (SEGEPLAN). Informe del Gobierno de Álvaro Colom, IV Informe del Presidente al Congreso de la República, enero 2012. Guatemala.

Guatemala Visible, monitoreo de medios, 2010. Guatemala.

Instituto Nacional de Estadística INE. Encuesta nacional de condiciones de vida. ENCOVI. 2011. Guatemala.

Instituto Nacional de Estadística y Consejo Nacional de la Juventud. Encuesta Nacional de Juventud. Gobierno de Guatemala, 2011. Guatemala.

Naciones Unidas. Acuerdo entre la Organización de las Naciones Unidas y el Gobierno de Guatemala relativo al establecimiento de una Comisión Internacional contra la Impunidad en Guatemala (CICIG), diciembre de 2006. Estados Unidos.

Naciones Unidas, Informe de la Décimo séptima conferencia de las Naciones Unidas sobre cambio climático. 2011. Sudáfrica.

Procuraduría de los Derechos Humanos. Informe sobre femicidios. Septiembre 2011. Guatemala.

Programa de Naciones Unidas para el Desarrollo (PNUD). Informe de Desarrollo Humano 2010. 2011, Guatemala.

Transparency International (Transparencia Internacional). Índice de Percepción de la Corrupción 2011.

Tribunal Supremo Electoral. Informe preliminar de las elecciones generales. Diciembre, 2011. Guatemala.

Universidad Rafael Landívar. Programa de Opinión Pública POP. Informes de la misión de observación electoral 2011. Guatemala.

USAC-URL-ASIES. Propuesta de Reforma Constitucional en Seguridad y Justicia, abril 2011. Guatemala. 


\section{Anexo}

\section{DATOS ELECTORALES 2011}

Resultados oficiales de las elecciones generales, primera vuelta electoral (11.09.2011).

\begin{tabular}{lc}
\hline Total de Empadronados: & 7.340 .841 \\
\hline Votos emitidos: & 5.022 .064 \\
Participación: & $68,4 \%$ \\
Abstencionismo: & $31,6 \%$ \\
Votos válidos (restando nulos y blancos): & 4.426 .931 \\
Votos nulos: & 212.814 \\
Votos en blanco: & 382.379 \\
\hline
\end{tabular}

Renzo Lautaro Rosal. Guatemalteco. Politólogo con especialización en Sociología Política. Maestría en Relaciones Internacionales (FLACSO/Universidad Rafael Landívar). Actualmente, Director de Incidencia Pública de la Universidad Rafael Landívar. Miembro del Foro Guatemala. presidente del Consejo Editorial y columnista del periódico digital Plaza Pública. Columnista del periódico Prensa Libre. Investigador de procesos electorales y políticas públicas. Analista político. Consultor en descentralización y gobiernos locales. Funcionario público en varias administraciones, habiendo sido Subsecretario Ejecutivo de la Presidencia, responsable del proceso de descentralización. Presidente de Rosal y Asociados, Political Consultants.

Email: rlrosal@yahoo.es 
